\title{
Demand For Electricity In Lebanon
}

Salah Abosedra, Lebanese American University, Beirut Campus, Lebanon Abdallah Dah, Lebanese American University, Beirut Campus, Lebanon Sajal Ghosh, Management Development Institute, Gurgaon, India

\begin{abstract}
This paper estimates the demand for electricity in Lebanon by employing three modeling techniques namely OLS, ARIMA and exponential smoothing for the time span January 1995 to December 2005. In- sample forecasts reveal that the forecasts made by ARIMA $(0,1,3)(1,0,0)^{12}$ is superior in terms of lowest RMSE, MSE and MAPE criteria, followed by exponential smoothing and OLS. Therefore, the planners in Lebanon could utilize linear univariate time-series models for forecasting future demand of electricity until detailed data on various socio-economic variables are available, which, in the future, may result in other modeling techniques being superior to estimate the demand for electricity in the country.
\end{abstract}

Keywords: Electricity Demand; Exponential Smoothing, ARIMA Modeling

\section{INTRODUCTION AND REVIEW OF RELATED STUDIES}

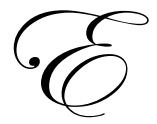

lectricity is one of the vital ingredients of socio-economic development of modern society. Demand for electricity is increasing rapidly, particularly in the developing countries. This increasing demand needs to be assessed properly to have a proper planning for this key infrastructure, so that the society gets the desired growth rate.

The nature of electricity differs from that of other commodities since electricity is a non-storable good and there have been significant seasonal and diurnal variations of demand. Precise estimation and forecasting of electricity demand can help in proper investment for new infrastructure as well as successful operation of all type of electrical utilities so that customer demands are met cost effectively. Accurate demand forecasts are also important for better scheduling of generating utilities and assessing system security.

Many studies in the literature have examined electrical energy consumption forecast and related topics, [Bernard et al., 1996 - Hsing, 1994 -Al-Faris, 2002 - Nasr et al., 2000], among others, estimated demand for electricity for various countries using different modeling techniques. Most such studies have investigated the impact of real income, price of electricity, price of substitute source of energy, population, temperature and other related variables, on the consumption of electricity.

Forecasting the demand for electricity in a country like Lebanon is very important for two reasons. First, so far, only few studies have dealt with issues related to various economic aspects of electricity consumption in Lebanon . Houri and Korfali (2005) used a sample of 509 households in Lebanon to study the residential energy consumption patterns in the country in relation to income, price, area of residency and number of occupants. Nasr, Badr \& Dibeh, (2000) investigated the determinants of electricity consumption (Imports and Degree Days) in Lebanon for the period 1993-1997. Cointegration analysis for the two sub-periods 1995-97 and 1996-97 revealed the existence of a long run relationship between the variables. In another study, Bader \& Nasr (2001) investigated cointegrating relationship between electricity consumption and climate factors, temperature, relative humidity and clearness index for the period 1992 - 1999. Saab, Badr \& Nasr (2001) used three univariate models namely autoregressive (AR), autoregressive moving average (ARMA) and an AR(1)/highpass Filter model to forecast electricity consumption in Lebanon using sample size Jan 1990 - May 1999. The study finds that the AR(1)/highpass Filter model produced the best forecast. In the present study, we have used a sample size for the time span January 1995 to December 2005, which is more recent than those used in the above-mentioned studies. 
Second, as mentioned earlier, a robust forecast of electricity demand is very important; as over estimation of demand could result in unnecessary huge investments in electric generations and transmission assets. Such a result would create more financial burdens in a country like Lebanon that is already struggling financially with one of the highest debt relative to its GDP. Alternatively, under estimation of the demand for electricity would lead to further future shortage of supply of electricity, a situation from which the country has already been suffering. It is very important, therefore, to select an appropriate demand estimation model that will provide precise estimates of future demand of electricity in Lebanon.

Keeping this in mind, this paper estimates the demand for electricity in Lebanon using three models namely ordinary least-square (OLS) estimation, where we use real imports (proxy for GDP), relative humidity and monthly degree days as independent variables, an autoregressive integrated moving average (ARIMA) model and an exponential smoothing model. Utilizing several performance criteria such as root mean square error (RMSE), mean square error (MSE) and mean absolute percentage error MAPE), we compare the forecasting performance of these three models and, finally, recommend the one with the best forecasting ability. This will help Electricite Du Liban (EDL), a financially-starved, state-owned company for generation and distribution of electricity in Lebanon, on making investment decisions and on scheduling the operation of the existing and new power plants so that the supply of electricity can be made adequate enough to meet the future demand and its variations in a cost effective manner.

The rest of the paper is organized as follows. Section 2 describes the data used in the study, and the econometrics methodology employed. This includes presenting the results of estimating the OLS, ARIMA and the exponential smoothing models. The criteria employed to assess their forecasting performance are also presented. Finally, section 3 contains the conclusion and the policy implications of our study.

\section{DATA ANALYSIS AND ECONOMETRIC METHODOLOGY}

\subsection{Description Of Data}

Our empirical estimations are conducted on monthly data for Lebanon covering the period January 1995 to December 2005. Monthly electricity consumption figures (in MWH) were obtained from Electricite Du Liban (EDL). Due to unavailability of monthly data on GDP or index of industrial production (IIP), monthly imports, as a proxy of economic activity, have been collected from the Central Bank of Lebanon. This is justified as others have used imports in previous studies as a proxy for GDP in the case of Lebanon (Nasr, Badr and Dibeh- 2000). The figures for imports were deflated using monthly CPI figures obtained from Bank Audi (Lebanon) to show real imports in terms of Dec. 1993 price level. Given the unavailability of data for an index of import prices, this was regarded as a good proxy. Relative humidity figures for the same time span are taken from various issues of the statistics Bulletins which are published by the Central Administration for Statistics of the Republic of Lebanon. Finally, data for degree days were calculated from temperatures figures for Beirut's (Capital) airport which were obtained from the Directorate General of Civil Aviation, the Ministry of Public Works and Transportation. The concept of degree days is used to evaluate energy demand for cooling and heating services as it measures of the average temperature's departure from a human comfort level .Using a base temperature of $15.6^{\circ} \mathrm{C}$, heating degree days (HDDs) are defined as $15.6-\mathrm{T}$, where $\mathrm{T}$ is the average temperature of a given day. Cooling degree days (CDDs) are calculated in a similar fashion with a base of 21.1. DD figures are then calculated as the sum of HDD and CDD.

\subsection{Regression Analysis}

First, we have tried to estimate electricity demand for Lebanon using ordinary least square (OLS) technique, where electricity consumption has been regressed on real import, relative humidity and monthly degreedays. The regression equation can be written as;

$E_{t}=a+b I_{t}+\mathrm{cH}_{t}+d D_{t}+u_{t}-------(1)$ 
where $E_{t}, I_{t}, H_{t}$ and $D D D_{t}$ are electricity consumption, real import, relative humidity and degree-days respectively at time $t$ and $\mathrm{u}_{\mathrm{t}}$ is the error term. a, b, c, d are the parameters to be estimated. The Durbin-Watson DW test is used to check for serial correlation of the error terms. A first order autoregressive term can be added as a correction measure, in case of rejection of the null hypothesis of no serial correlation, which can be represented as

$u_{t}=r_{t-1}+e_{t}-----------(2)$

In Eq. 2, u represents the unconditional residuals, $e$ is the innovation in the disturbance and $r$ is an estimate of the first-order autocorrelation coefficient.

Results of the regression analysis are shown in Table 1. t-statistics show that all the explanatory variables are statistically significant at $10 \%$ level. We have introduced AR(1) term in order to get rid of serial correlation and is found to be statistically significant.

Table 1: Results of regression analysis

\begin{tabular}{ccccc}
\hline Variable & Coefficient & Std. Error & t-Statistic & Prob. \\
\hline C & 484.1888 & 91.14418 & 5.312339 & 0.0000 \\
I & 0.205195 & 0.079282 & 2.588179 & 0.0108 \\
H & 2.804077 & 0.988340 & 2.837160 & 0.0053 \\
DD & 0.132162 & 0.071212 & 1.855911 & 0.0658 \\
AR(1) & 0.894722 & 0.035795 & 24.99555 & 0.0000 \\
\hline R-squared & 0.823038 & Akaike info criterion & 11.09172 \\
Adjusted R-squared & 0.817420 & Schwarz criterion & 11.20146 \\
Durbin-Watson stat & 2.234085 & F-statistic & 146.5040 \\
\hline
\end{tabular}

\subsection{Univariate Time-Series Forecasting}

$\operatorname{ARIMA}(p, d, q)(P, D, Q)_{s} \operatorname{model} ;$

These models take into account the effect of trend and seasonal fluctuations of a time series and are expressed as;

$\Phi_{\mathrm{p}}\left(\mathrm{L}^{\mathrm{s}}\right) \phi_{\mathrm{p}}(\mathrm{L})\left(1-\mathrm{L}^{\mathrm{s}}\right)^{\mathrm{D}}(1-\mathrm{L}){ }^{\mathrm{d}} \mathrm{X}_{\mathrm{t}}=\Theta_{\mathrm{Q}}\left(\mathrm{L}^{\mathrm{s}}\right) \theta_{\mathrm{q}}(\mathrm{L}) \mathrm{u}_{\mathrm{t}}$.

where $X_{t}$ is the original series, $L$ is the backward shift operator, $\phi$ and $\theta$ are autoregressive (AR) and moving average (MA) parameters while $\Phi$ and $\Theta$ are seasonal AR and MA parameters. D \& d represent order of seasonal and non-seasonal differencing.

Box-Jenkins methodology has been exploited to identify the most suitable ARIMA model. Box-Jenkins considers model building as iterative processes which can be divided into four stages: identification, estimation, diagnostic checking and forecasting.

The sample autocorrelation function and partial autocorrelation function have been used to identify the possible values of the regular part of the model, i.e., autoregressive order $\mathrm{p}$ and moving average order $\mathrm{q}$ in a univariate ARMA model along with the seasonal part, which has then been estimated by maximum likelihood. The residuals are inspected for any remaining autocorrelation and as shown in Table 2, the residual series appears to be purely random. 
Table 2: Check for randomness of residual series

\begin{tabular}{ccccc} 
Lag & AC & PAC & Q-Stat & Prob \\
\hline 5 & 0 & 0.001 & 0.4867 & 0.485 \\
6 & 0.09 & 0.093 & 1.5116 & 0.47 \\
7 & 0.12 & 0.124 & 3.3481 & 0.341 \\
8 & 0.018 & 0.026 & 3.3898 & 0.495 \\
9 & 0.072 & 0.084 & 4.0686 & 0.54 \\
10 & 0.092 & 0.093 & 5.1814 & 0.521 \\
11 & -0.017 & -0.019 & 5.2204 & 0.633 \\
12 & -0.139 & -0.148 & 7.8238 & 0.451 \\
13 & 0.061 & 0.023 & 8.3327 & 0.501 \\
14 & 0.035 & -0.003 & 8.5015 & 0.58 \\
\hline
\end{tabular}

It has been found that $\operatorname{ARIMA}(0,1,3)(1,0,0)^{12}$ is the best fitted model in terms of smallest Akike Information Criterion (AIC) and Schwarz Bayesiam Criterion (SBC) to explain the electricity consumption in Lebanon. The estimated parameters with their standard error, $t$ statistics and probability values are shown in table 3 .

Table 3: Estimated parameters of ARIMA $(0,1,3)(1,0,0)^{12}$ model

\begin{tabular}{lcccc}
\multicolumn{1}{c}{ Variable } & Coefficient & Std. Error & t-Statistic & Prob. \\
\hline SAR(12) & 0.60776 & 0.049518 & 12.27351 & 0 \\
MA(1) & -0.439432 & 0.090587 & -4.850941 & 0 \\
MA(2) & -0.342475 & 0.094218 & -3.63492 & 0.0004 \\
MA(3) & -0.206988 & 0.091576 & -2.260298 & 0.0257 \\
AIC $=\mathbf{1 0 . 6 1}$, SBC $=\mathbf{1 0 . 7}$, DW-Statistics $=\mathbf{2 . 0 2}$ & & & \\
\hline
\end{tabular}

\section{Exponential Smoothing}

Exponential smoothing methods are relatively simple but robust approaches to forecasting. Three basic variations of exponential smoothing are commonly used: simple exponential smoothing (Brown, 1959); trendcorrected exponential smoothing (Holt, 1957); and Holt-Winters' method (Winters, 1960). In our case, HoltWinters- Multiplicative method has been considered as this method is appropriate for series with a linear time trend and seasonal variation. The smoothed series is given by

$$
\hat{X}_{t+k}=(a+b k) c_{t+k} \ldots \ldots . .(5)
$$

where, $\mathrm{a}, \mathrm{b}$ and $\mathrm{c}$ are intercept, trend and multiplicative seasonal coefficients, which are defined by the following recursions

$$
\begin{aligned}
& a(t)=\alpha \frac{y_{t}}{c_{t}(t-s)}+(1-\alpha)[a(t-1)+b(t-1)] \\
& b(t)=\beta[a(t)-a(t-1)]+(1-\beta) b(t-1) \\
& c_{t}(t)=\gamma \frac{y_{t}}{a(t)}+(1-\gamma) c_{t}(t-s)
\end{aligned}
$$

where $0<\alpha, \beta, \gamma<1$ are the dumping factors and $\mathrm{s}$ is the seasonal frequency. Forecasts are computed by

$$
\hat{X}_{t+k}=[a(T)+b(T) k] c_{T+k-s} \ldots \ldots \text { (6) }
$$

Results of the smoothing procedure are shown in Table 4. Part 1 shows the estimated parameter values. Zero values for $\beta$ and $\gamma$ mean that the trend and seasonal components are estimated as fixed and not changing. Part 2 
of the table displays the mean $(\alpha)$ and trend $(\beta)$ at the end of estimation period that are used for post-sample smoothed forecasts along with seasonal factors $(\gamma)$.

Table 4: Results of the smoothing procedure

\begin{tabular}{|c|c|c|c|}
\hline \multirow{5}{*}{ Part 1: } & $\alpha$ & & 0.75 \\
\hline & $\beta$ & & 0 \\
\hline & $\gamma$ & & 0 \\
\hline & Mean & & 840.3058 \\
\hline & Trend & & 4.809896 \\
\hline \multirow{12}{*}{ Part 2: } & Seasonals: & $2003 \mathrm{M} 12$ & 1.080618 \\
\hline & & 2004M01 & 1.093654 \\
\hline & & 2004M02 & 0.974851 \\
\hline & & 2004M03 & 1.010674 \\
\hline & & 2004M04 & 0.920833 \\
\hline & & 2004M05 & 0.949392 \\
\hline & & 2004M06 & 0.939005 \\
\hline & & 2004M07 & 1.013154 \\
\hline & & 2004M08 & 1.040303 \\
\hline & & 2004M09 & 0.998387 \\
\hline & & $2004 \mathrm{M} 10$ & 1.014658 \\
\hline & & $2004 \mathrm{M} 11$ & 0.964472 \\
\hline
\end{tabular}

\subsection{Forecasting Performance}

The following figure shows the in-sample forecasts of electricity consumption made by OLS, HoltWinters- Multiplicative exponential smoothing method and ARIMA $(0,1,3)(1,0,0)^{12}$ along with actual data ranging from December 2004 to December 2005. It has been found that in-sample forecasts made by ARIMA (0, .1, 3) $(1,0,0)^{12}$ is superior in terms of smallest RMSE criteria (42.06) followed by exponential smoothing (RESE = 49.35) and OLS (RMSE = 72.02). Other diagnostic criteria like AIC, SBE etc. also indicate the superiority of ARIMA model.

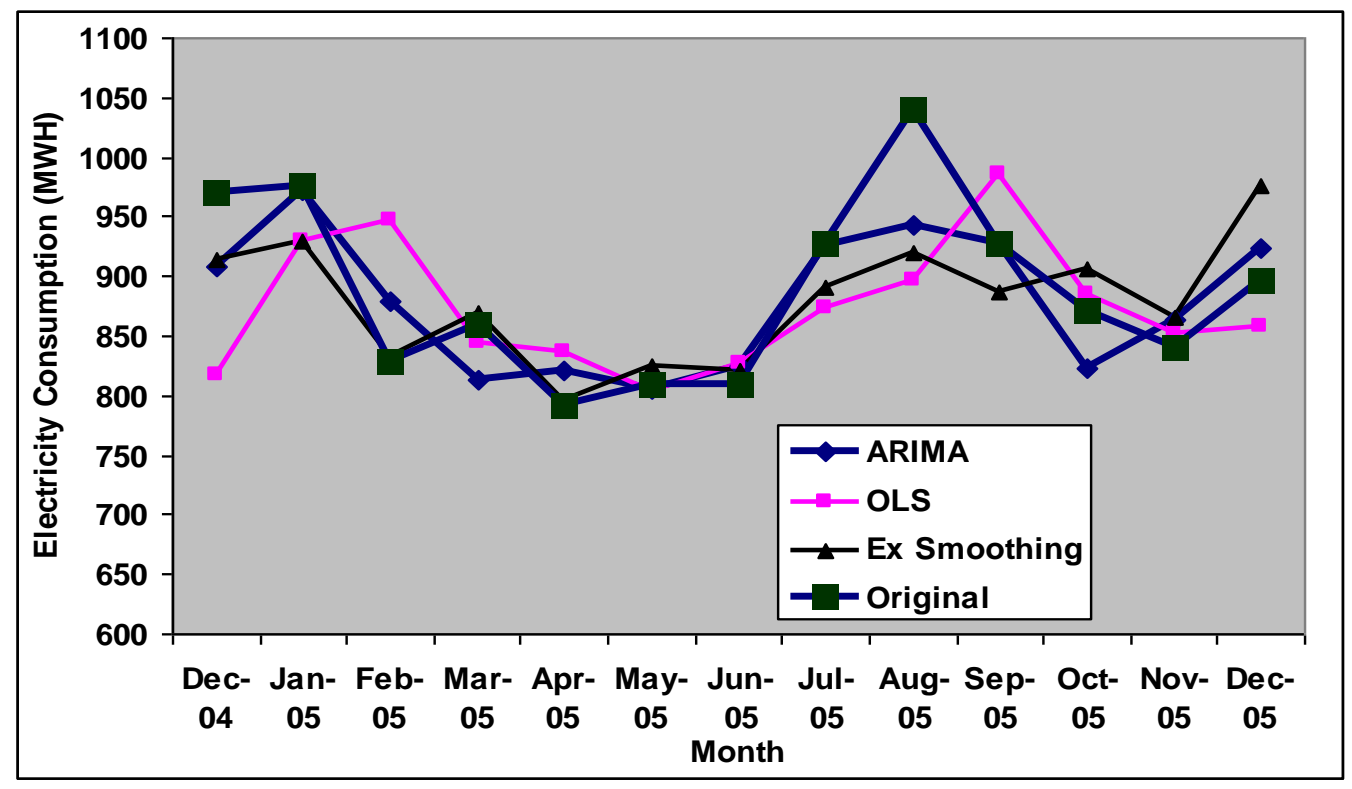




\section{Conclusion and policy implications}

Given the importance of electricity in the reconstruction process of Lebanon, this study employs three models to investigate the demand for electricity in Lebanon, utilizing monthly data from January 1995 to December 2005. Such an investigation should be useful in providing an accurate, robust and understandable forecast for electricity demand in the country.

Three models were estimated in this study, including ARIMA, OLS and exponential smoothing. In-sample forecasts reveal that the forecasts made by ARIMA $(0,1,3)(1,0,0)^{12}$ is superior in terms of lowest RMSE, MSE and MAPE criteria, followed by exponential smoothing and the OLS. The results produced are satisfactory given the unavailability of data on the price of electricity, real GDP and price of substitute source of energy. Therefore, the planners in Lebanon could utilize linear univariate time-series models for forecasting future demand of electricity until detailed data on various socio-economic variables are available, which, in the future, may result in other modeling techniques being superior to estimate the demand for electricity in the country.

\section{AUTHOR INFORMATION}

Salah Abosedra is chair of the Department of Economics and Finance, School of Business, Lebanese American University (LAU), in Beirut, Lebanon. The author, who holds a B.S. from the University of Libya, earned M.A. degrees in both finance (University of Florida) and economics(University of Colorado at Boulder) and a Ph.D. in economics from the latter institution. Earlier, the author conducted research at the International Monetary Fund, held a Fulbright Fellowship at the University of Qatar, and was Chair of the Economics Department at both Wesley College (Delaware) and the United Arab Emirates University. Dr Abosedra's articles have appeared in such publications as Applied Energy, Energy Policy, Applied Financial Economics, OPEC Review, Journal of Business \& Economics Research, The Middle East Business And Economic Review, and The Journal of Energy and Development.

Abdallah Dah, the former chair of the Department of Business at Lebanese American University, earned a B.A. in business studies from the Lebanese University, M.A. \& Ph.D. in economics from the University of Colorado (Boulder), where he also served as an instructor of economics. The author's publications have appeared in such venues as Applied Energy, The International Journal of Economics \& Finance, The International Hospitality, Leisure \&Tourism Management Journal, International Journal of Business \& Economics, and The Journal of Energy \& Development.

Sajal Ghosh is an Assistant Professor of Economics in Management Development Institute, India. He earned his Ph.D. in Engineering, M. Tech in Energy Science and Technology, and M. Phil in Development Studies. His industry experience spans for six years. He is a member of CII National Council of Energy and ex-member of World Energy Council's International Study Group on 'Energy Market Reforms'. He has several publications in the international journal of reputes. His areas of interests are applied econometrics, demand forecasting, energy market reforms, power market, macroeconomics and clean technologies.

\section{REFERENCES}

1. Al-Faris, A. 2002. "The demand for electricity in the GCC countries." Energy Policy 30, 117 - 124.

2. Badr, E. and Nasr, G. 2001. "On the relationship between electrical energy consumption and climate factors in Lebanon: co-integration and error-correction models." International Journal of Energy Research 25, 1033-1042.

3. Bernard, J., Bolduc,D., and Belanger, D. 1996. "Quebec residential electricity demand: a microeconomic approach." Canadian Journal of Economics 29, 92 - 113.

4. Ghosh, S. 2002. "Electricity consumption and economic growth in India."Energy Policy 30, 125-129.

5. Houri, A. and Korfali,S. 2005. "Residential energy consumption patterns: The case of Lebanon."International Journal of Energy Research 29, 755-766.

6. Hsing, Y. 1994. "Estimation of residential demand for electricity with the cross sectionally correlated and time-wise autoregressive model." Resource and Energy Economics 16, 255 - 263. 
7. Nasr, G., Badr, E., and Dibeh, G. 2000. "Economic modeling of electricity consumption in post-war Lebanon.” Energy Economics 22, 627-640.

8. Saab, S., Badr, E., and Nasr, G. 2001. "Univariate modeling and forecasting of energy consumption: the case of electricity in Lebanon." Energy 26, 1-14.

9. Wolde-Rufael, Y. 2006. "Electricity consumption and economic growth: a time series experience for 17 African counties." Energy Policy 34, 1106-1114.

\section{NOTES}


NOTES 